\title{
Mídia e consumo nas vozes das crianças: a produção de corpos infantis
}

\author{
Joice Araújo Esperança \\ Paula Costa Ribeiro \\ Universidade Federal do Rio Grande
}

\section{Resumo}

Neste artigo, discute-se a produção de infâncias em face da centralidade assumida pelo consumo nos processos de constituição identitária que se engendram no cenário contemporâneo. A partir das narrativas de um grupo de crianças, problematiza-se a produção de corpos infantis, destacando a importância da aparência, da exposição da imagem pessoal e da posse de mercadorias para as atuais configurações de infância. 0 estudo ancora-se nas ferramentas conceituais disponibilizadas por Zygmunt Bauman em seu exame acerca da modernidade líquida e do advento da sociedade de consumidores. As análises evidenciam a imbricação entre mídia e consumo na reinvenção dos sentidos e das experiências de infância.

Palavras-chave: Infâncias. Consumo. Corpo. Mídia. 


\section{Media and consumption in the voices of children: the production of children's bodies}

This study discusses the production of childhoods in view of the centrality taken on by consumption in the processes of identity construction that are engendered in the contemporary scene. Drawing on the narratives of a group of children, the production of children's bodies is analyzed with a focus on the importance of appearance, the exhibition of the personal image, and the ownership of goods, in the current forms of childhood. The study is grounded on the conceptual tools provided by Zygmunt Bauman in his analysis of liquid modernity and the advent of consumer society. The discussion shows the overlap between media and consumption in the reinvention of the meanings and experiences of childhood.

Keywords: Childhood. Consumption. Body. Media.

\section{Los medios de comunicación y el consumo en las voces de los niños: la producción de los cuerpos de los niños}

En este estudio se discute la producción de la infancia en vista de la centralidad atribuida por el consumo en los procesos de construcción de la identidad que se engendran en el escenario contemporáneo. A partir de los relatos de un grupo de niños, se discute la producción de los cuerpos con un enfoque en la importancia de la apariencia, la exhibición de la imagen personal y la propiedad de bienes en la configuración actual de la infancia. El estudio se basa en las herramientas conceptuales dadas a conocer por Zygmunt Bauman en su análisis de la modernidad líquida y el advenimiento de la sociedad de consumo. La discusión muestra la imbricación de los medios de comunicación y el consumo en la reinvención de los sentidos y las experiencias de la infancia.

Palabras clave: Infancia. Consumo. Cuerpo. Medios de comunicación. 


\section{Um ponto de partida: as infâncias como construções em permanente mudança}

Iniciamos este artigo refletindo sobre as formas consensuais e naturalizadas de significar as crianças, que remetem à identificação de aspectos uniformes e ideais e, portanto, à ideia de infância como um dado universal e atemporal. Dentre esses aspectos, figuram a frequência às instituições educativas, o brincar, a dependência e a obediência aos adultos e também o resguardo diante de temas como a morte, a sexualidade ou a violência. Entretanto, se examinarmos as condições de existência das crianças em outros momentos históricos, veremos que a imbricação entre infância, educabilidade e escolarização nem sempre existiu e que outros parâmetros de interação moldavam as relações entre adultos e crianças em um passado não muito longínquo, quando a delimitação das classes de idade e a definição do que é próprio ou impróprio para cada uma delas não eram motivos de preocupação ou vigilância.

Com essas considerações introdutórias, buscamos enfatizar que os modos correntes de pensar acerca das crianças podem assumir uma feição óbvia e inquestionável no cotidiano das relações sociais, embora tenham sido engendrados por processos históricos e culturais delineados no decurso da modernidade ocidental, como evidenciam as abordagens desenvolvidas por Postman (1999) e Narodowski (2001), dentre outros estudiosos da infância. Seguindo a trilha aberta pelos referidos pesquisadores, neste artigo abordamos os modos de perceber, tratar e educar as crianças como fenômenos que variam conforme as épocas, os lugares, as crenças, os saberes, as normas, os valores e as atitudes que forjam a vida individual e coletiva no contexto dos diversos grupos sociais. Assim, compreendemos as possibilidades de ser criança e viver a infância como construções que se articulam aos sistemas de significado culturalmente instituídos e às formas de sociabilidade que se configuram no interior de uma conjuntura histórica. Sob esse enfoque, Dornelles e Bujes (2012, p. 14) destacam:

Pensar a infância como uma invenção nos permite entender não apenas como e por que mudam as suas concepções, mas também como são diferentes, de uma época para outra, as próprias crianças [...]. Assim, compreender que a infância tem um significado diferente, sendo marcada em cada sociedade e em cada época por sinais próprios, possibilita que se atribua a esse conceito o caráter de uma construção social e se ponha em questão a sua universalidade.

0 entendimento das infâncias como construções, forjadas por circunstâncias históricas e socioculturais, torna-se fundamental para o propósito deste 
trabalho, em que buscamos problematizar a produção das infâncias no cenário contemporâneo, considerando a centralidade assumida pelo consumo nos processos de constituição identitária e nas formas de convívio humano. A partir das narrativas de um grupo de crianças, problematizamos a produção de corpos infantis, explorando as ferramentas conceituais disponibilizadas por Zygmunt Bauman, em seu exame acerca da modernidade líquida e do advento da sociedade de consumidores.

Na próxima seção, abordamos o esmaecimento das fronteiras geracionais na modernidade líquida, destacando as formas variáveis de perceber e intervir sobre os corpos dos sujeitos e os marcadores identitários que se inscrevem neles. $\mathrm{Na}$ continuidade do trabalho, discorremos sobre os significados e práticas que produzem os corpos das crianças na transição de uma sociedade orientada pela produção para uma sociedade regulada pelo consumo. Em seguida, apresentamos a abordagem metodológica que subsidiou a realização da pesquisa e analisamos como diversas práticas de consumo intervêm sobre os corpos infantis na atualidade.

\section{Infâncias, corpos e consumo: o esmaecimento de fronteiras geracionais em tempos de modernidade líquida}

Se os ideais de inocência e heteronomia ainda orientam as formas como percebemos e relacionamo-nos com as crianças, não raras vezes vivenciamos situações que colocam em questão nossas mais sólidas certezas, evidenciando que as noções e experiências de infância não são fixas ou irrevogáveis, mas estão abertas à contínua reinvenção. A metáfora da liquidez empregada por Bauman (2001) para descrever o atual estágio da modernidade torna-se útil para compreendermos a fluidez de alguns pontos de referência que definiam a infância, como a demarcação de fronteiras que separavam o mundo infantil do mundo adulto e que sustentavam a ordem hierarquizada entre as gerações. Os ideários abrangentes e totalizantes que permitiam segregar as categorias de idade, estabelecendo padrões e regras, a fim de garantir a homogeneidade das condutas, parecem cada vez mais inoperantes para a compreensão da vida conduzida na contemporaneidade.

De acordo com Bauman (2001; 2007), na modernidade líquida, quadros de referência, formas de agir, crenças, convicções e estilos de vida encontram-se em permanente fluxo e mudam antes que possam se solidificar em costumes, hábitos ou verdades autoevidentes. Além da aceleração das mudanças, o autor esclarece que a privatização dos deveres e das escolhas também constitui uma marca do 
ambiente líquido-moderno, em que valores e ideais coletivos cedem espaço a estratégias de vida e a interesses individuais, regidos pela lógica do consumo. 0 esmaecimento das distinções que particularizavam as crianças e distanciavamnas do mundo adulto assume estreita relação com os deslocamentos sinalizados por Bauman (2001), pois a individualização das escolhas, dos estilos de vida e a intensificação das formas de consumo possibilitam experiências de infância cada vez mais plurais e diversificadas. Nesse panorama, as tentativas de categorização dos grupos etários tornam-se, mais do que nunca, contingentes e circunstanciais. Num tempo marcado pela instabilidade e pela incerteza, as atitudes, os comportamentos, as ocupações, as preferências e até mesmo a aparência física de adultos e crianças por vezes tornam-se indistinguíveis (Postman, 1999). Isso pode ser evidenciado por meio da análise dos significados e práticas que produzem os corpos infantis na atualidade.

0 crescimento acelerado do mercado de produtos infantis voltados para os cuidados com o corpo' sinaliza que as crianças contemporâneas não estão alheias às interpelações da publicidade e dos mercados de bens de consumo, que irradiam a preocupação com a imagem pessoal e oferecem uma infinidade de mercadorias específicas para o aprimoramento da aparência dos pequenos consumidores. Essas constatações sugerem que os modos de perceber e agir sobre os corpos assumem diferentes feições, variando conforme os tempos, as culturas e as condições societárias.

Nessa direção, Bauman e May (2010) destacam que as formas como pensamos e atuamos sobre nossos corpos não têm lugar em um vácuo sociocultural. Ao discorrerem sobre os corpos e a vida em sociedade, os autores ressaltam que, embora algumas propriedades físicas possam ser herdadas e, portanto, não resultem de escolhas e ações intencionais, as convenções e códigos compartilhados socialmente levam-nos a constituir formas de lidar com nossos corpos que sejam reconhecidas como "certas" e "apropriadas". Bauman e May (2010, p. 167) afirmam que "Assim, a forma do corpo, a maneira como nos vestimos e arrumamos, além de nosso modo de andar, são mensagens para os outros". De acordo com Bauman e May (2010), na vida em sociedade, nossos corpos são dotados de significados particulares que afetam a maneira como nos vemos e como os outros nos veem. Esses significados não se separam das categorias biológicas e da materialidade corpórea, mas interagem com elas para constituírem o que somos, fomos e viremos a nos tornar.

Nessa perspectiva, Veiga-Neto (2000) salienta a articulação entre elementos

1. Conforme destaca a reportagem publicada em fevereiro de 2009 pela revista IstoÉ, sob o título Vaidade não tem tamanho, o mercado brasileiro de cosméticos infantis é o segundo maior do mundo, com aproximadamente 50 milhões de consumidores. 
biológicos, históricos e culturais que operam na construção dos corpos, ao argumentar que os marcadores identitários, isto é, os símbolos culturais que funcionam para diferenciar, agrupar e classificar os sujeitos, inscrevem-se fundamentalmente no corpo. Sendo assim, é sobretudo no corpo que se tornam manifestas as marcas que nos posicionam, tais como a estatura, o peso, a cor da pele, o sexo, a idade, etc. 0 corpo também é constituído e expressa costumes, crenças e tradições compartilhadas pelos grupos sociais; sobre ele inscrevem-se sinais que evidenciam os pertencimentos a um território, a uma geração ou a uma classe social. Contudo, os marcadores identitários não são estáveis ou perenes e recombinam-se continuamente, formando conexões variáveis e historicamente contingentes.

As proposições de Bauman (2001) sobre a transição da modernidade sólida para a modernidade líquida permitem levar adiante essas reflexões, pois colocam em destaque as relações de interdependência entre o corpo social e os corpos individuais, explicitando redirecionamentos nos processos de organização da vida coletiva e de constituição identitária dos sujeitos. Ao examinar as condições que caracterizam a modernidade, Bauman (2005) identifica a formação de dois arranjos societários, designados como sociedade de produtores e sociedade de consumidores. Assim, o autor sinaliza uma importante mudança de ênfase, ou de prioridade, que se translada da esfera da produção para a esfera do consumo. Importa salientar que essa mudança não segue a lógica da substituição, pois nenhuma sociedade pode se sustentar sem que, pelo menos, alguns de seus membros produzam coisas a serem consumidas; todos eles indubitavelmente também consomem (Bauman, 2005). Contudo, embora não se trate de uma ruptura, ou de uma súbita transformação, o passo que vai da sociedade de produtores à sociedade de consumidores implica profundas alterações nas formas de inserção social dos sujeitos, incluindo os investimentos sobre seus corpos.

As formas de perceber e intervir sobre os corpos infantis, que se implementaram no contexto da família e da instituição escolar modernas, coadunam-se com as demandas políticas e econômicas da sociedade de produtores. A esse respeito, Bauman (2007) esclarece que a maneira como uma sociedade admite e molda seus novos membros - as crianças - depende do tipo de atividade que os indivíduos dessa sociedade são convocados a desempenhar em seu serviço ativo. No caso da sociedade de produtores, o conformismo e a interiorização de hábitos, como regularidade e disciplina, eram as virtudes a serem cultivadas e promovidas desde a mais tenra idade. Essa sociedade concentrava-se na administração e educação dos corpos infantis para adequá-los ao seu futuro "habitat": o recinto da fábrica ou o campo de batalha. (Bauman, 2007)

Percebidas como futuros produtores, que não tinham concluído o processo 
de crescimento, as crianças deveriam ser preparadas para a vida adulta. Assim, passaram a ser identificadas como aprendizes ou alunos; submetê-las ao período de escolarização vinculou-se ao projeto de sociedade em construção. Nessa linha de argumentação, Pereira (2002) destaca que a visão da criança como um ser incompleto e dependente do adulto consolidou-se na medida em que ela não estava, de fato, inserida no sistema produtivo, aspecto central para o desenvolvimento do capitalismo. Assim, conforme a referida autora, a infância tornou-se símbolo de pureza, livre das implicações do mundo do trabalho, ao mesmo tempo em que foi associada à ideia de futuro, sendo vista a partir do que supostamente se tornaria.

Esse quadro modifica-se com o advento da sociedade de consumidores, isto é, quando o potencial de consumo, e não mais a capacidade produtiva, fornece a principal interface entre os indivíduos e a sociedade como um todo (Bauman, 2008). De forma distinta do que acontece no sistema produtivo, o engajamento na esfera do consumo não deve ser postergado para o futuro, mas promovido e intensificado entre todas as classes de idade. Nessa direção, Stearns (2006) destaca que as mudanças transcorridas no decurso da modernidade estão relacionadas à redefinição do papel econômico das crianças. De acordo com o autor, esse processo pode ser identificado pelo movimento de retirada das crianças do mundo do trabalho e pela progressiva ampliação do ingresso da população infantil na instituição escolar. Em linhas gerais, isso significa que aos poucos as crianças abandonam a posição de ativo econômico e passam a representar, sobretudo, fonte de investimentos e custos para a família e o Estado.

Numa sociedade regulada pelo consumo, os corpos infantis passam a ser construídos e modificados por incontáveis investimentos, que não se restringem aos contextos da família e da escola, mas são promovidos por múltiplas instâncias culturais. Dentre essas instâncias, a mídia assume papel de destaque, interpelando as crianças como consumidores efetivos, informados e insaciáveis, desde os primeiros anos de vida. A centralidade ocupada pela mídia é um dos elementos relacionados à alteração dos significados e práticas que operam na construção dos corpos na sociedade de consumidores, isso porque o corpo torna-se o principal local de inscrição dos atos de consumo e um dos territórios mais explorados pelo marketing e pela publicidade.

Sendo assim, no caminho que conduz à sociedade de consumidores, as exigências colocadas no corpo do produtor/soldado, isto é, a adaptação às rotinas monótonas, a prudência e a tolerância no adiamento da satisfação, tornam-se inoperantes para a construção do corpo do consumidor. "O segundo tipo de corpo difere enormemente do primeiro por ser um valor-fim, ou um valor-destino, em vez de portar um significado meramente instrumental." (Bauman, 2007, p. 120) De acordo com Bauman (2011), o corpo consumista é, acima de tudo, um receptor de 
sensações e prazeres; a medida de sua adequação é a capacidade de consumir o que a sociedade tem a oferecer. Desse modo, a preocupação com a saúde cede espaço à busca pela boa forma, mudança de ênfase que mobiliza os consumidores a procurarem soluções e receitas de aperfeiçoamento disponíveis no mercado.

Assim, a adesão, ou não, às práticas de consumo que são agregadas aos corpos infantis demarca importantes formas de distinção e pertencimento no interior dos grupos sociais. As possibilidades de cuidar, adornar, embelezar os corpos e por meio deles ostentar o potencial de consumo tornam-se aspectos decisivos na constituição identitária das crianças contemporâneas. No seguimento deste artigo, tais problematizações serão retomadas e aprofundadas a partir da análise das narrativas de um grupo de crianças, produzidas no desenvolvimento de uma pesquisa no espaço escolar.

\section{Investigando narrativas de crianças dos Anos Iniciais}

As reflexões focalizadas neste trabalho, sobre a produção de corpos infantis na sociedade de consumidores, foram desencadeadas pela análise das narrativas de crianças, na faixa etária de 8 a 12 anos, estudantes de uma escola da rede pública do município de Rio Grande/RS. Ao todo, 95 crianças participaram de encontros realizados em sala de aula, no decorrer do segundo semestre letivo de $2010^{2}$. A investigação narrativa foi a abordagem metodológica que pautou a realização dos encontros com as crianças na escola. De acordo com Connelly e Clandinin (1995), a investigação narrativa consiste no estudo da forma como os seres humanos experimentam o mundo, por meio da construção e reconstrução de histórias pessoais e coletivas.

Para viabilizar a estratégia de contar, ouvir e contrapor histórias foram propostas algumas atividades que provocaram as crianças a refletir e dialogar sobre suas experiências de consumo. Integraram essas atividades a produção de autorretratos, por meio dos quais as crianças representaram quem ou como gostariam de ser, seguida de conversas conduzidas em pequenos grupos.

No processo de análise das narrativas buscamos tecer relações de sentido entre as histórias contadas pelas crianças e as circunstâncias históricas e práticas socioculturais que possibilitaram a sua composição. Sendo assim, os relatos das crianças não serão tratados como expressão de um falante singular ou como revelação de uma interioridade privada, mas em articulação com outras

2. Cada criança escolheu um nome fictício para figurar na pesquisa, procedimento que assegura o anonimato no processo de análise do material empírico. 
histórias, (re)produzidas e (re)inventadas nas redes de comunicação das quais as crianças participam em diversos contextos: na família, na escola, na mídia, etc. 0 delineamento dessa estratégia de análise pautou-se nas contribuições de Jorge Larrosa sobre narrativa e identidade.

De acordo com Larrosa (1996), o sentido de quem somos e do que nos acontece é análogo à construção e à interpretação de um texto narrativo, que obtém seu significado a partir de relações de interdependência e intertextualidade que mantém com outros textos, assim como de seu funcionamento pragmático em um contexto. Nessa perspectiva, ao elaborar, contar e ouvir histórias, aprendemos quem somos e quem são os outros, num processo complexo em que a pessoa descreve a si mesma em contraste com as demais, construindo sua identidade e suas relações com o mundo. Assim, a constituição narrativa dos sujeitos e de suas experiências "não é algo que se produza em um solilóquio, em um diálogo íntimo do eu consigo mesmo, mas em um diálogo entre narrativas, entre textos". (Larrosa, 2008, p. 70)

Partindo dessas compreensões, neste artigo focalizamos um aspecto recorrente nas narrativas das crianças: as imbricações entre mídia, moda, consumo e a produção de corpos infantis. Assim, buscamos examinar a correlação entre as histórias contadas pelas crianças e os textos midiáticos que permeiam seu cotidiano, destacando a ênfase atribuída ao aprimoramento da aparência, à exposição da imagem pessoal e ao consumo de mercadorias na composição dos sentidos que expressam sobre si e os outros. 0 movimento analítico empreendido consiste em problematizar os vínculos que interligam as experiências narradas pelas crianças com os modos de existência que adquirem visibilidade nos espaços da mídia e que interpelam os sujeitos infantis a operarem sobre seus corpos por meio de diversas práticas de consumo.

\section{Eu queria ter um corpo assim, igual a esse da revista...}

A fala que intitula esta seção foi expressa por uma menina, durante os primeiros encontros da pesquisa realizados na escola. Nesses encontros, solicitamos às crianças que imaginassem quem ou como gostariam de ser, produzindo um autorretrato, por meio de desenho ou colagem, para contarem suas histórias e dialogarem com uma das pesquisadoras ${ }^{3}$. Ao optar pelo emprego de recortes em

3. Os diálogos foram gravados e transcritos mediante a autorização das crianças e de seus responsáveis, obtida por meio da assinatura de um Termo de Consentimento que informava sobre os objetivos e os procedimentos da pesquisa. 
suas produções, as crianças procederam à seleção das revistas ${ }^{4}$, conforme suas preferências. A partir dessas escolhas, pôde-se constatar uma estreita relação entre os conteúdos das revistas e as vivências infantis. Os meninos demonstraram interesse pela revista Placar e o jornal Zero Hora, os quais apresentavam informações sobre clubes e jogadores de futebol, esporte que praticavam na escola e fora dela. Para as meninas, o conteúdo das revistas Capricho, Boa Forma e Atrevida mostrou-se mais atrativo e muitas delas revelaram ser leitoras dos referidos suportes textuais, expondo à pesquisadora os exemplares que carregavam em suas mochilas.

Por meio do acesso a revistas, as meninas mantinham-se informadas sobre bandas musicais e a vida de atores de séries televisivas, temas que permeavam suas interações, como as conversas, as brincadeiras, as trocas de fotos, pôsteres e figurinhas. Essas observações evidenciam que a seleção das revistas não se deu ao acaso, mas em razão dos interesses e experiências compartilhados entre pares. As escolhas das crianças também sinalizam que as produções midiáticas apresentam estratégias que interpelam meninos e meninas de modos distintos, reproduzindo formas de estabelecer e compreender as diferenças de gênero ${ }^{5}$ vigentes nas práticas sociais. Isso porque os textos da mídia não operam isoladamente, mas em articulação com outros textos, que compõem o "gigantesco e agitado conjunto de histórias que é a cultura”. (Larrosa, 2008, p. 70)

Nesse sentido, também é importante destacar que a relação entre as narrativas das crianças e o intercâmbio de significados possibilitado pelo contato com as produções midiáticas não se constituíram à parte das condições socioculturais que caracterizam a sociedade de consumidores e que incidem na construção das experiências de infância. Seguindo essa linha de pensamento, Kellner (2001) enfatiza que mídia e consumo operam como princípios organizadores das sociedades contemporâneas, pois, além do incremento da oferta de bens materiais, o que define o cenário atual é a profusão de imagens, sons e espetáculos que compõe uma cultura comum para a maioria dos indivíduos em diferentes regiões do mundo. Ao destacar a centralidade dos sistemas simbólicos midiáticos nas sociedades de consumo, Kellner ressalta que seus textos fornecem materiais que forjam condutas e identidades, constituindo as formas como os sujeitos veem-se

4. Foram disponibilizadas às crianças revistas de circulação nacional, tais como Veja, IstoÉ, Caras, Cláudia, Galileu, Capricho, Atrevida, Boa Forma e Placar. Além desses materiais, as crianças tiveram acesso a edições dos jornais Zero Hora, Diário Gaúcho e Agora. As revistas e os jornais empregados nos encontros da pesquisa foram publicados entre os anos de 2009 e 2010.

5. Neste trabalho, compreendemos que as formas de representar e distinguir o feminino e o masculino não são determinadas por características puramente biológicas, pois os modos de ser e agir de homens e mulheres, meninos e meninas, são construídos e ressignificados em articulação com as circunstâncias históricas e as formas de organização da vida em sociedade los códigos morais, as leis, as tradições, as crenças, os saberes, etc.). 
e veem os outros, as maneiras como pensam, sentem e comportam-se, o que passam a acreditar, temer e desejar.

Apresentando ideias afins, Fischer (2003) argumenta que a mídia configurase como um território privilegiado para a construção de aprendizagens diversas, pois é parte integrante e fundamental dos processos de produção e circulação de significações e sentidos relacionados aos modos de ser, pensar e conhecer o mundo. De acordo com a autora, os artefatos midiáticos possibilitam o acesso a histórias, ou formas de narrar a vida em sociedade, que simultaneamente traduzem-nos e produzem-nos. Ao investigar esses artefatos, Fischer (1999; 2003) identifica a prevalência de temas relacionados ao corpo e às formas de aprimorálo, condição que se interliga às narrativas das crianças participantes da pesquisa, que referenciam o corpo e a beleza como alvos prioritários de seus desejos e aspirações. Isso pode ser observado nas narrativas que seguem:

Goku (8 anos): Eu estou procurando um corpo forte, eu queria ter um corpo bem forte, musculoso, igual ao do Goku [personagem de desenho animado japonês].

Pesquisadora: Por que tu gostarias de ter um corpo assim?

Goku (8 anos): Porque eu acho bonito.

D'Alessandro ( 9 anos): Eu também estou procurando uma foto de um homem bem fortão. Eu queria ser o mais bonito do mundo, do planeta.

Pesquisadora: Por que tu gostarias de ser assim, tão bonito?

D’Alessandro (9 anos): Porque daí todo mundo iria gostar de mim.

Goku (8 anos): Alguém tem um corpo bem forte pra me dar?

D’Alessandro (9 anos): Achei um, o Ronaldinho Gaúcho [jogador de futebol].

Emanuele (9 anos): Eu queria ter um corpo assim, igual a este da revista.

Pesquisadora: Por quê?

Emanuele ( 9 anos): Porque ela é muito bonita, sempre magrinha, sempre se alimentando bem... Eu adoro ela [refere-se à imagem de uma atriz com a barriga à mostra que protagoniza o anúncio de um produto para redução de peso].

Pesquisadora: 0 que tu mudarias em ti para te pareceres com ela?

Emanuele ( 9 anos): Eu queria mudar em mim a minha barriga, porque eu sou gordinha, a minha barriga é grande. Aí eu iria ficar com a barriga bem lisinha. Faz de conta que eu sou ela, dá para fazer $\mathrm{o}$ antes e o depois, o antes e o depois...

Como se pode perceber, não é de qualquer corpo que as crianças falam ao contraporem suas histórias às imagens buscadas ou selecionadas nas revistas. Trata-se, sobretudo, de um corpo qualificado como bonito. Embora nas falas dos meninos a ideia de beleza esteja associada à força e ao vigor físico, enquanto nas falas das meninas o foco recaia sobre a esbelteza, em ambos os casos fala-se de 
um corpo que inspira cuidados com a aparência, seja para livrar-se da gordura ou para ter músculos delineados; nos dois casos os critérios que definem o corpo bonito e socialmente desejável são estabelecidos pelas imagens de personagens e de ídolos em evidência nos espaços da mídia. Por meio dessas imagens, presentes em seu cotidiano, as crianças aprendem a preterir e admirar alguns corpos, assim como a rejeitar e desqualificar outros; aprendem que a beleza habita os corpos de alguns poucos (magros, musculosos, atléticos, jovens), que são aclamados pela mídia como exemplos a serem seguidos. Quanto a esse ponto, a fala de um menino merece destaque. Ao escolher a revista Placar e descartar as revistas Veja e IstoÉ, o menino justificou: “Essas revistas não têm nada, não têm pessoas" (Zico, 9 anos). Nesse momento, mostraram-se ao menino duas imagens, uma de um casal de idosos e outra de um ministro. Diante da insistência de uma das pesquisadoras, o menino respondeu: "Mas não tem as pessoas que eu quero, só tem gente feia".

Os pontos de ligação entre as narrativas das crianças também expressam a busca pela boa forma, problematizada por Bauman $(2007$; 2011) ao discorrer sobre os modos de perceber e de lidar com os corpos, que se engendram na sociedade de consumidores. As análises de Bauman levam à compreensão de que o corpo é lançado a uma posição única à medida que a intensificação das sensações, prazeres e alegrias proporcionadas pelos mercados de consumo caminha para o centro da vida. Na sociedade de consumidores, o próprio corpo passa a ser percebido como uma propriedade privada, suscetível à contínua transformação e aperfeiçoamento. Assim como as demais mercadorias em oferta, o corpo deve ser exibido, admirado, consumido. 0 corpo em forma passa a significar o que o corpo saudável significava na sociedade de produtores: condição de pertencimento e inserção social. Por isso, é desejável esculpir suas formas e intervir sobre sua imagem para tornar aparentes algumas marcas de reconhecimento que o tornam digno de aprovação. “Uma vez que o corpo também transporta uma mensagem, não lhe basta estar em forma; ele precisa parecer em forma. Para disso convencer quem o observa, ele deve ser magro, elegante, ágil. (Bauman; May, 2010, p. 164)

A busca pela boa forma, como outros esforços de identificação que se inscrevem na lógica da sociedade líquido-moderna, mantém os consumidores em acelerado e permanente movimento. 0 ideal de boa forma toma o corpo como um instrumento aberto às sensações e satisfações, imediatas e transitórias, que não podem ser fixadas e que não reconhecem limites. De acordo com Bauman (2011, p. 159-160), “a boa forma do corpo não é um fim que possa ser alcançado, e não há nenhum momento no horizonte em que se possa dizer com clara convicção: consegui”. Quando os sujeitos são avaliados pelos parâmetros que definem a boa forma, há sempre novas possibilidades, escolhas e soluções a serem desejadas e testadas para tornar os corpos ainda mais belos e graciosos. Para isso, os sujeitos devem 
estar sempre dispostos a mudar, seja o comprimento dos cabelos, a cor dos olhos ou o formato dos dentes, conforme mostram as narrativas das meninas:

Pesquisadora: Vamos conversar sobre quem ou como vocês gostariam de ser? Então me contem...

Miley 2 ( 9 anos): Eu gostaria de ter os olhos azuis.

Demi Lovato 3 (10 anos): Eu queria ter os olhos verdes.

Pesquisadora: Por quê?

Miley 2 ( 9 anos): Porque é bonito!

Pesquisadora: Mas apenas os olhos verdes e azuis são bonitos?

Miley 2 (9 anos): É mais bonito, eu gosto mais do azul, eu vi numa artista, na TV.

Pesquisadora: E tu lembras quem era essa artista?

Miley 2 (9 anos): Não, não me lembro, mas eu lembro que vi.

Pesquisadora: Mas os olhos a gente não pode mudar.

Miley 2 ( 9 anos): Pode sim, com umas lentes!

Pesquisadora: Tem mais alguma coisa que gostarias de falar sobre a tua colagem?

Miley 2 (9 anos): Eu também queria mudar meus dentes, eu queria ter os dentes pequenos.

Pesquisadora: $\mathrm{E}$ tu, por que fizeste essa colagem?

Isabela (9 anos): Eu? Todo mundo diz que eu sou bonita, mas eu me acho feia.

Pesquisadora: Por quê?

Isabela ( 9 anos): Ah, já que todo mundo diz que eu sou bonita, eu quero ser ainda mais bonita.

Pesquisadora: E por que tu gostarias de ser mais bonita?

Isabela (9 anos): Ah, não sei...

Pesquisadora: 0 que tu achas que falta para ficares mais bonita?

Isabela (9 anos): Eu queria ter o cabelo liso, uma franja...

Como sugerem as falas das meninas, os imperativos da mudança e da novidade que regem a sociedade de consumidores exigem que os corpos sejam continuamente remodelados, seguindo as tendências adotadas pelos artistas que figuram nas capas de revistas, nos palcos e nos programas de TV. Essas figuras públicas da modernidade líquida, que obtêm notoriedade e alcançam a fama na mesma velocidade com que são esquecidas e relegadas ao anonimato, oferecemse como exemplos com os quais as crianças aprendem como obter uma resposta favorável dos outros. Num mundo regulado pelo consumo, a busca ávida por exemplos e receitas de vida torna-se uma das variedades do comprar e, como tal, deve ser praticada infatigavelmente (Bauman, 2001). À medida que os interesses privados e as satisfações pessoais tornam-se objetivos perseguidos com ardor, a 
ponto de concentrarem-se prioritariamente nos corpos individuais, os mártires e heróis de outrora cedem espaço a uma figura central nas histórias compartilhadas em sociedade: a celebridade.

Conforme argumenta Bauman (2011), a importância de uma celebridade é avaliada pela visibilidade de sua presença e não pelo peso de seus feitos. Segundo o autor, numa sociedade marcada pela proeminência de imagens como meio de comunicar ideias, os sujeitos são levados a crer que o que conta, acima de tudo, é ser visto por uma multiplicidade de pessoas. Nesse contexto, estabelece-se um modo de estratificação social característico da modernidade líquida: a divisão entre os que são vistos e os anônimos, isto é, as pessoas que permanecem à sombra dos poucos proclamados pela mídia como extraordinários. Essa divisão fica evidente nas falas das crianças ao expressarem o desejo de ser ou de se parecer com cantores, atores, modelos, apresentadores e jogadores de futebol. Em suas justificativas, além do encantamento pela forma física e pela aparência de seus ídolos, as crianças mencionaram reiteradas vezes o desejo de serem famosas. É o que explicitam as seguintes narrativas: "Eu queria ser a Deborah Secco porque ela é bonita, alta e famosa" (Nicole, 10 anos); "Eu queria ser um jogador de futebol e ser muito rico e famoso" (Luís Fabiano, 9 anos); "Eu queria ser famosa e eu queria ser ela [mostra a capa da revista Boa Forma], porque ela é bonita, magra, tem olhos verdes, os cabelos compridos e porque ela é apresentadora do Vídeo Show". (Gabriela Montez, 9 anos)

Como praticantes da vida para o consumo, uma vida marcada pela intensificação da produção e circulação de imagens, as crianças portavam em suas mochilas câmeras fotográficas digitais e celulares que possibilitavam o registro e a visualização imediata de imagens de si e dos colegas de sala de aula. Quando isso acontecia, as crianças pareciam estar sempre prontas para compor uma cena e experimentar um breve instante de fama: faziam poses, reproduziam trejeitos adotados por seus ídolos, agregavam aos seus corpos óculos e bonés coloridos. Além disso, antes de serem fotografadas, as meninas encolhiam a barriga para parecerem mais magras, enquanto alguns meninos inflavam o peito ou cruzavam os braços para parecerem fortes; outros dobravam as mangas da camiseta do uniforme escolar para exporem suas tatuagens temporárias. Segundo as próprias crianças, essas fotografias eram postadas em seus perfis no site da rede social Orkut ${ }^{6}$; pode-se supor que essa prática possibilitava-lhes aparições públicas e a sensação de serem notadas, admiradas, comentadas. Sobre a afeição por tirar fotos, uma menina explicou:

6. No ano de 2010, quando foram realizados os encontros da pesquisa, o Orkut era o principal site de rede social utilizado pelos internautas brasileiros. 
Demi Lovato 3 (8 anos): Eu queria muito uma câmera porque eu amo tirar foto!

Pesquisadora: Por que tu gostas tanto assim?

Demi Lovato 3 (8 anos): Para se mostrar, para todo mundo te ver... Sabias que no Natal eu vou ganhar um violão?

Pesquisadora: É mesmo? Tu sabes tocar violão?

Demi Lovato 3 (8 anos): É, eu quero ser cantora. Eu estou até fazendo uma dieta.

Pesquisadora: Por quê?

Demi Lovato 3 (8 anos): Ah, eu queria ser que nem a Demi Lovato [cantora e atriz], ser famosa.

Pesquisadora: Por que tu gostarias de ser famosa?

Demi Lovato 3 (8 anos): Porque todo mundo fica na tua volta, imagina, dar autógrafos, todo mundo te ver, imagina que legal!

Pesquisadora: Tu irias gostar de dar autógrafos?

Demi Lovato 3 (8 anos): Eu ia, sabe? Às vezes aqui no colégio eu dou, porque eu sou do grupo de dança e vêm umas gurias e me pedem. O R. também dá autógrafos porque ele é da banda, mas ele dá menos que eu, porque ele recém-entrou para a banda.

A busca por notoriedade, fama e riqueza, enfatizada pelas crianças participantes da pesquisa, inter-relaciona-se com o processo de comoditização do consumidor, problematizado por Bauman (2008). Conforme o autor, o ambiente existencial que se tornou conhecido como sociedade de consumidores "se distingue por uma reconstrução das relações humanas a partir do padrão, e à semelhança, das relações entre os consumidores e os objetos de consumo" (Bauman, 2008, p. 19). Nesse sentido, Bauman questiona a soberania do consumidor, isto é, sua descrição como alguém que decide, julga, calcula, avalia e escolhe, de forma racional e autônoma, levando em conta desejos estabelecidos num plano puramente privado. Assim, ao analisar os redirecionamentos que configuram as atuais formas de consumo, o autor coloca em questão a ideia de separação entre as coisas a serem consumidas e os seres humanos que as consomem, enfatizando que a sociedade de consumidores caracteriza-se precisamente pelo embaçamento, ou pela eliminação, da distinção entre consumidores e mercadorias. Partindo dessas proposições, é possível identificar nas narrativas das crianças a referência a um corpo-mercadoria, cuja imagem deve distinguir-se, destacar-se e atrair atenção, tal como as mercadorias disponíveis nas vitrines das lojas, nas telas de TV ou nos sites de compras.

Para manter o valor de mercado, o corpo deve reunir atributos físicos avaliados, ainda que temporariamente, como corretos e adequados. 0 marketing e a publicidade são as principais instâncias responsáveis por instilar o medo da inadequação, esse sentimento que acompanha os membros da sociedade de consumidores 
e que é reanimado regularmente desde a mais tenra idade. De forma insidiosa e sedutora, as campanhas publicitárias convidam os consumidores a comparar cada detalhe de seus corpos com as infinitas possibilidades de aperfeiçoamento ofertadas pelos mercados de bens de consumo. De acordo com Bauman (2007), a ansiedade em torno dos cuidados com o corpo tornou-se uma fonte de lucros potencialmente inexaurível; os anúncios comerciais fazem o possível para intensificar a insegurança que prometem combater. Isso porque toda promessa é desabilitada assim que novos anseios tomam o lugar dos antigos e os produtos recém-lançados substituem ou associam-se aos anteriores.

0 consumo de produtos para o embelezamento dos corpos é um tema recorrente nas narrativas das meninas, que expressam formas de nomear e classificar o corpo feminino em concordância com os padrões identificados nas campanhas publicitárias. Assim, ao contarem histórias sobre quem ou como gostariam de ser, as meninas mencionaram as imagens de mulheres presentes em comerciais de maquiagens, perfumes e cremes para a pele e os cabelos. Frequentemente, as meninas explicitaram insatisfação em relação aos seus corpos, avaliando-os a partir de oposições, por meio das quais classificavam o que era bonito/feio, bom/ ruim, considerando algumas marcas presentes nos corpos midiáticos, como o cabelo liso e o rosto maquiado, livre de imperfeições. É o que explicita o diálogo a seguir:

Melina ( 9 anos): Eu desenhei um gloss porque eu amo batom!

Pesquisadora: Ah, tu gostas de maquiagem?

Melina (9 anos): Eu adoro! Eu desenhei umas mulheres com batom na boca e o batom do lado, assim, fechado. Quando eu vejo uma propaganda eu fico com vontade de usar o batom e eu peço para a minha mãe comprar, daí a minha mãe disse que é da Avon. Esse aqui é da Avon, oh! Eu tenho esse sem marca, esse da Moranguinho.

Juliana Paes (8 anos): Eu desenhei o creme Seda, porque eu adoro a mulher da propaganda, eu gosto do cabelo dela, fica bem lisinho, é bem fácil de pentear. Eu queria ter o cabelo liso.

Pesquisadora: Por que tu querias ter o cabelo liso?

Juliana Paes (8 anos): Porque é bonito, todo mundo fala, assim, que eu tenho "cabelo ruim", até o meu pai diz que eu tenho "juba de leão".

Pelas falas das meninas, é possível identificar que, além da mídia e da publicidade, outras instâncias, como a família, estão implicadas na produção das narrativas que versam sobre um corpo feminino socialmente desejável. Nos ditos das meninas, as informações sobre marcas de batom e a afeição por um tipo de cabelo associam as imagens dos textos midiáticos às vivências familiares. Com 
isso, pode-se constatar que algumas marcas corporais e práticas de consumo - como ter cabelos lisos, adquirir e usar maquiagem - relacionam-se com as convenções e códigos sociais reproduzidos em diversas instâncias educativas, que instituem as possibilidades de ser criança e viver a feminilidade no contexto de uma sociedade de consumidores. Dessa forma, as meninas parecem assumir os cuidados com a aparência como um dever e uma responsabilidade perante si mesmas, pois, como elas afirmaram: “Não é só beleza que tem que ter, mas tem que ser bonita" (Lilly, 8 anos); "Eu gosto de ser charmosa, usar roupa bonita, me arrumar, usar perfume, cuidar do corpo, da pele, das unhas, me arrumar, me pintar". (Perla, 9 anos)

Nas composições das crianças, o esmaecimento das distinções entre ser e ter, entre consumidores e mercadorias, também se evidencia por meio da importância atribuída ao vestuário e à posse de alguns bens materiais, denominados pelas crianças como itens da moda. Entre esses itens, que eram agregados à superfície dos corpos, destacavam-se óculos, brincos e pulseiras coloridas, bolsas e relógios que acompanhavam calçados infantis, além de bonés, anéis e correntes. Essas mercadorias operavam como marcadores identitários, ou símbolos de pertença, cuja posse condicionava hierarquias, privilégios e permitia o acesso a algumas interações, como rodas de conversa e brincadeiras em que se realizavam empréstimos e permutas. Ao conversar com as crianças sobre as semelhanças identificadas entre as peças de roupa e os adornos coloridos acoplados a seus corpos, foi possível constatar que o uso dessas mercadorias articulava-se ao acesso às informações sobre marcas, preços, locais de venda e, sobretudo, estilos e tendências que adquirem proeminência nos espaços da mídia. É o que explicita o diálogo abaixo, em que uma menina justifica a importância da moda como fator de agregação social:

Pesquisadora: Vocês todas usam esses brincos coloridos, né?

Barbie (9 anos): É, todo mundo usa porque é moda.

Pesquisadora: Essas pulseiras coloridas também, todas as meninas aqui da sala usam, né?

Barbie (9 anos) Na verdade, isso [aponta para as pulseiras coloridas] era de prender o cabelo, só que o Restart [banda musical] começou a usar de pulseira.

Pesquisadora: Ah, os cantores da banda Restart usam?

Barbie (9 anos): É, eles começaram a usar de pulseira e daí agora todo mundo usa assim.

Pesquisadora: Ah, entendi. E vocês usam mais alguma coisa dessa banda?

Barbie ( 9 anos): Ah, todo mundo usa as coisas coloridas da moda Restart. Tem óculos, calça, tênis, relógio, boné... 
Pesquisadora: E o que é moda para ti?

Barbie (9 anos): É o que todo mundo usa!

Como sugerem os ditos e as ações das crianças, a adesão a algumas práticas de consumo, como o vestuário e os acessórios coloridos que adornavam seus corpos, articula-se com a busca por reconhecimento e aceitação no contexto da escola. Desse modo, portar os símbolos adotados pelas figuras midiáticas, cultivando uma imagem pública de si que atende aos preceitos efêmeros da moda, significa compartilhar códigos de sociabilidade que permitem às crianças situar-se umas em relação às outras. Nesse sentido, o fenômeno da moda não se reduz às práticas indumentárias, mas, como ressalta Maffesoli (2010), faz referência a um tempo social. De acordo com o autor, nas sociedades atuais, a moda segue o ritmo rápido e pontuado que encontra expressão nos diversos meios de comunicação, constituindo um sistema de significações compartilhado. Assim, para as crianças participantes da pesquisa, estar em dia com as tendências de estilo e tê-las inscritas em seus corpos significa, dentre outras coisas, fazer parte do grupo escolar. Isso pode ser percebido nas narrativas: "Todo mundo usa o que a moda faz porque ninguém vai querer ficar de fora" (Robinho, 10 anos); "0 primeiro motivo para eu comprar uma coisa é se os meus amigos têm" (Naruto, 8 anos). Essas narrativas assumem sentido no contexto de uma sociedade em que os sujeitos buscam nas mercadorias atributos capazes de incrementar seu valor social e a garantia de acesso à comunidade de consumidores, que percebem e tratam seus corpos como produtos de comodificação.

\section{Que corpo é esse? Que infância é essa?}

Nos limites deste artigo, analisamos as narrativas de um grupo de crianças, problematizando as relações de interdependência entre a produção dos corpos infantis, os textos midiáticos e a expansão do fenômeno do consumo. Com isso, buscamos compor uma leitura sobre as infâncias produzidas na sociedade de consumidores. Tendo como fio condutor a compreensão das infâncias como construções em permanente mudança, sinalizamos alguns redirecionamentos nas formas de perceber e intervir sobre os corpos infantis que se engendram em correlação com as atuais formas de consumo. Esses redirecionamentos tornam as fronteiras entre os mundos infantil e adulto mais tênues e maleáveis do que em outros tempos, embora isso não signifique o apagamento das distinções entre as classes de idade. Mas, a despeito das continuidades que ainda sustentam uma noção hegemônica de infância, somos constantemente confrontados com 
modos de ser criança plurais e diversos, que escapam às tentativas de apreensão totalizantes.

As infâncias produzidas na sociedade de consumidores, não raras vezes, provocam desconforto entre nós, professores e pesquisadores, atentos às experiências das crianças e estupefatos diante de sua contínua reinvenção. Isso porque, se as referências e os padrões de convivência entre as gerações sempre estiveram abertos à mudança, nada se compara ao ritmo e à intensidade com que essas transformações vêm sendo experimentadas no ambiente líquidomoderno. Nesse ambiente existencial, as crianças não se fixam às experiências conduzidas pela escola ou determinadas por seus pais ou professores. Ao invés disso, elas transitam com certa independência entre os mundos infantil e adulto, estabelecendo pontos de contato entre universos simbólicos que se tornam intercambiáveis e suscetíveis a influências mútuas. Os corpos das crianças participantes da pesquisa tornam visíveis esses pontos de contato, expondo as marcas de práticas de consumo que primam pelo aperfeiçoamento da aparência, expressando o anseio por notoriedade e distinção.

0 que pensar/fazer diante desse quadro? Lamentar o que as crianças deixaram de ser e o quanto elas se distanciam da criança que um dia fomos? De que serve a nostalgia celebrada pelos adultos, senão para fortalecer o sentimento de impotência que nos acomete quando constatamos a força exercida pelo mercado e pela mídia na educação das crianças contemporâneas? A capacidade de desestabilizar essas forças exige de professores e pesquisadores o exercício da crítica diante dos interesses que mobilizam as indústrias do entretenimento e que socializam as crianças para uma vida de consumo. E esse exercício de crítica implica assumir o compromisso de repensar as infâncias e seus modos de educação nesses tempos de incerteza.

\section{Referências}

BAUMAN, Zygmunt. Modernidade Líquida. Rio de Janeiro: Jorge Zahar, 2001. . Trabajo, consumismo y nuevos pobres. Barcelona: Gedisa, 2005.

Vida líquida. Rio de Janeiro: Jorge Zahar, 2007.

Vida para consumo: a transformação das pessoas em mercadoria. Rio de Janeiro: Jorge Zahar, 2008.

Vida em fragmentos: sobre a ética pós-moderna. Rio de Janeiro: Jorge Zahar, 2011.

Zahar, 2010.

; MAY, Tim. Aprendendo a pensar com a sociologia. Rio de Janeiro: Jorge 
CONNELLY, Michael; CLANDININ, Jean. Relatos de experiencia e investigación narrativa. In: LARROSA, Jorge et al. Déjame que te cuente. Barcelona: Laertes, 1995.

DORNELLES, Leni Vieira; BUJES, Maria Isabel. Alguns modos de significar a infância. In: DORNELLES, Leni Vieira; BUJES, Maria Isabel (Orgs.). Educação e infância na era da informação. Porto Alegre: Mediação, 2012.

FISCHER, Rosa Maria Bueno. Mídia e produção de sentidos: a adolescência em discurso. In: SILVA, Luiz Heron da (Org.). A escola cidadã no contexto da globalização. Petrópolis: Vozes, 1999.

. Televisão e educação: fruir e pensar a TV. Belo Horizonte: Autêntica, 2003. KELLNER, Douglas. A cultura da mídia. Estudos Culturais: identidade e política entre o moderno e o pós-moderno. São Paulo: Edusc, 2001.

LARROSA, Jorge. Narrativa, identidad y desidentificación. In: LARROSA, Jorge. La experiencia de la lectura. Barcelona: Laertes, 1996.

. Tecnologias do eu e educação. In: SILVA, Tomaz Tadeu (Org.). 0 sujeito da educação: estudos foucaultianos. Petrópolis, RJ: Vozes, 2008.

MAFFESOLI, Michel. No fundo das aparências. Rio de Janeiro: Vozes, 2010.

NARODOWSKI, Mariano. Infância e poder: conformação da pedagogia moderna. Bragança Paulista: Editora da Universidade São Francisco, 2001.

PEREIRA, Rita Marisa Ribes. Tudo ao mesmo tempo agora: considerações sobre a infância no presente. In: GONDRA, José Gonçalves (Org.). História, infância e escolarização. Rio de Janeiro: 7Letras, 2002.

POSTMAN, Neil. O desaparecimento da infância. Rio de Janeiro: Graphia, 1999.

STEARNS, Peter. A infância. São Paulo: Contexto, 2006.

VEIGA-NETO, Alfredo. As idades do corpo: (material)idades, corporal(idades), ident(idades). In: AZEVEDO, Pablo Gentili (Org.). Utopia e democracia na educação cidadã. Porto Alegre: Ed. Universidade/UFRGS, 2000.

Recebido em outubro de 2013

Aprovado em dezembro de 2013

Joice Araújo Esperança é doutora em Educação Ambiental pela Universidade Federal do Rio Grande (Furg) e professora do Instituto de Educação da mesma Universidade. E-mail: joiceesplayahoo.com.br.

Paula Costa Ribeiro é doutora em Ciências Biológicas pela Universidade Federal do Rio Grande do Sul (UFRGS) e professora do Instituto de Educação da Universidade Federal do Rio Grande (Furg). E-mail: pribeirolahotmail.com. 